\title{
Análise da produção acadêmica sobre a avaliação na/da Educação Infantil do período 2000-2012
}

\author{
Analysis of the academic production on evaluation \\ in/of Early Childhood Education in the \\ period 2000-2012
}

\section{Análisis de la producción académica sobre la evaluación en/de la Educación Infantil en el período 2000-2012}

\author{
Graciele Glap* \\ Mary Ângela Teixeira Brandalise** \\ Ademir José Rosso***
}

\begin{abstract}
Resumo: Este artigo é originário de uma pesquisa de natureza qualitativa, do tipo estado da arte, que teve um caráter inventariante de produções científicas sobre avaliação na/da Educação Infantil, coletadas por meio de consulta eletrônica e de produções impressas, publicadas no período de 2000 a 2012. Foram localizados 47 trabalhos, sendo 24 artigos, 20 dissertações e 3 teses. Os resumos dos trabalhos foram analisados por meio do software ALCESTE, e o corpus de análise articula-se em torno de duas categorias: avaliação na Educação Infantil, voltada às pesquisas sobre avaliação no contexto micro escolar, e avaliação da Educação Infantil, referente ao contexto meso e macro escolar, ou seja, à avaliação das políticas/programas e instituições.
\end{abstract}

Palavras-chave: Avaliação na/da Educação Infantil. Estado da arte. Infância.

\begin{abstract}
This article is originated from a qualitative research, state of the art type, which had an inventory character derived from scientific papers on evaluation in/of Early Childhood Education, collected through electronic consultation and printed productions, published from 2000 to 2012. 47 works were found, of which 24 were articles, 20 were dissertations and 3 were theses. The abstracts of these works were analyzed using the ALCESTE software, and the corpus analysis is structured in two categories: evaluation in Early Childhood Education, directed to researches on evaluation in the micro school context, and evaluation of Early Childhood Education, related to the

\footnotetext{
* Mestre em Educação pelo Programa de Pós-Graduação em Educação da Universidade Estadual de Ponta Grossa. E-mail: <gracieleglap@hotmail.com>

** Professora da Universidade Estadual de Ponta Grossa. E-mail: <marybrandalise@uol.com.br>

*** Professor da Universidade Estadual de Ponta Grossa. E-mail: <ajrosso@uepg.br>
} 
meso and macro school context, that is to say, the evaluation of policies/programs and institutions.

Keywords: Assessment in/of Early Childhood Education. State of the art. Childhood.

Resumen: Este artículo surge de una investigación de naturaleza cualitativa, del estilo de un estado del arte, que tuvo la intención de inventariar las producciones científicas sobre evaluación en/de la Educación Infantil, recolectadas por medio de consulta electrónica y de producciones impresas publicadas entre el 2000 y el 2012. Fueron localizados 47 trabajos, siendo 24 artículos, 20 investigaciones de maestrías y 3 tesis doctorales. Los resúmenes de los trabajos fueron analizados por medio del software ALCESTE y el corpus del análisis se articula en torno de dos categorías: evaluación en la Educación Infantil, vinculada a las investigaciones sobre evaluación en el contexto micro escolar, y evaluación de la Educación Infantil, referente al contexto meso y macro escolar, o sea, a la evaluación de las políticas/programas e instituciones.

Palabras-claves: Evaluación en/de la Educación Infantil. Estado del arte. Infancia.

\section{Introdução}

Nas últimas décadas, as discussões sobre infância vêm aumentando, tanto em grupos de pesquisa bem como nos programas de pós-graduação stricto sensu na produção de teses e dissertações e, ainda, na publicação de artigos em periódicos e eventos especializados. A carência de estudos e de pesquisas sobre a produção de conhecimento na área de Avaliação na/da Educação Infantil ainda se constitui um desafio para professores, pesquisadores e, também, formuladores de políticas/programas/projetos voltados à Educação Infantil, razões que originaram o desenvolvimento da pesquisa Avaliação na/da Educação Infantil: estado da arte 2000-2012, em nível de mestrado no PPGE/UEPG. ${ }^{1}$

Neste artigo, apresentamos uma sistematização da produção científica realizada entre 2000 e 2012 em torno desse tema e uma análise crítica dos resumos dos trabalhos coletados, buscando identificar os focos de interesse dos pesquisadores e, ao mesmo tempo, as lacunas ou as restrições existentes nesse campo de investigação.

Iniciamos explicitando alguns fundamentos teóricos sobre Infância, Educação Infantil e Avaliação Educacional. Na sequência, apresentamos os procedimentos metodológicos adotados na pesquisa e o programa ALCESTE, que

\footnotetext{
${ }^{1}$ A dissertação de mestrado Avaliação na/ da Educação Infantil: estado da arte 2000-2012, de autoria de Graciele Glap, foi desenvolvida no Programa de Pós-Graduação em Educação da Universidade Estadual de Ponta Grossa, sob orientação da professora Dr ${ }^{\mathrm{a}}$ Mary Ângela Teixeira Brandalise e financiada pela CAPES.
} 
processou o conteúdo dos resumos na busca dos objetos de pesquisa abordados nas produções científicas inventariadas, e, a partir das informações geradas nos relatórios do programa, foi realizada a análise dos dados para as devidas considerações finais.

\section{Infância, Educação Infantil e Avaliação Educacional}

Dialogar com as questões que envolvem a infância e a educação das crianças brasileiras não é tarefa fácil. As concepções de infância e de criança presentes na contemporaneidade foram tecidas durante anos e a várias mãos, sob diferentes enfoques e perspectivas. Da mesma forma, a Educação Infantil constitui-se um processo histórico, político, cultural e social.

A preocupação com a criança pequena, com a infância e com a Educação Infantil vem se consolidando nas políticas públicas e na legislação do Brasil desde 1988; em especial com a Constituição Brasileira, que, em seu artigo $7^{\circ}$, inciso XXV, determinou como direito social dos pais trabalhadores urbanos e rurais a assistência gratuita aos filhos e dependentes desde o nascimento até os cinco anos de idade em creches e pré-escolas (BRASIL, 1998). A Educação Infantil ficou definida na Carta Magna como primeiro espaço de educação coletiva da criança, fora do ambiente familiar. Outras iniciativas vieram na direção de dar identidade para a educação das crianças pequenas, como é o caso da Lei de Diretrizes e Bases da Educação Nacional, Lei no 9.394, de 20 de dezembro de 1996, em seu artigo 29, que incluiu a creche e a pré-escola ao sistema educacional brasileiro como primeira etapa da Educação Básica, com a finalidade de propiciar o desenvolvimento integral da criança em seus aspectos físico, afetivo, intelectual, linguístico e social complementando a ação da família e da comunidade (BRASIL, 1996).

Recentemente, o Projeto de Lei no 8.035/2010, relativo ao Plano Nacional de Educação 2011-2020, também afirma o dever do Estado com a educação e o direito da criança à Educação Infantil, sendo a matrícula/frequência das crianças de 0 a 3 anos (creche) opção da família, e a das crianças de 4 e 5 anos de idade é obrigatória (pré-escola), em conformidade com a Constituição Federal, alterada pela Emenda Constitucional no 59/2009 (BRASIL, 2009).

A Educação Infantil, nas Diretrizes Curriculares Nacionais para a Educação Infantil, definida pela Resolução CNE/CEB no 5, de 17 de dezembro de 2009 , em seu artigo $5^{\circ}$, é caracterizada como espaços institucionais não domésticos, públicos ou privados, que educam e cuidam de crianças de 0 a 5 anos de idade no período diurno, em jornada integral ou parcial, regulados e supervisionados por órgão competente do sistema de ensino e submetidos ao controle social (BRASIL, 2010). No centro do currículo, a criança é considerada sujeito histórico e de direitos que, nas relações, nas práticas e nas interações cotidianas, 
vivencia, constrói sua identidade pessoal e coletiva, brinca, imagina, fantasia, deseja, aprende, observa experimenta, narra, questiona e constrói sentidos sobre a natureza e sobre a sociedade. Essas concepções de educação para crianças pequenas devem fundamentar as concepções de ensino-aprendizagem, consequentemente, de avaliação na Educação Infantil para que, de fato, o professor possa acompanhar o desenvolvimento da criança a partir dos pressupostos legais, ou seja, do processo educativo destinado a promover continuadamente o desenvolvimento infantil.

As relações sociais estabelecidas no interior da escola são resultantes de processos e situações compartilhadas entre os sujeitos desse cenário educativo. São relações de poder desencadeadas a partir de situações cotidianas e, também, das ações avaliativas desenvolvidas. A escola pode contribuir para que as experiências com a avaliação possam marcar positiva ou negativamente a vida escolar e pós-escolar de seus alunos, pode reforçar as relações de poder existentes dentro de uma sociedade desde a sala de aula ou agir como elemento de socialização e de mediação. A avaliação, portanto, serve a propósitos diferentes, podendo estar relacionada a interesses e a objetivos administrativos, ou a propósitos e a interesses educacionais e pedagógicos (AFONSO, 2000). A avaliação educacional não pode limitar-se aos processos de ensino e aprendizagem, mas sim considerar o processo educativo em sua totalidade.

Nessa perspectiva, a avaliação educacional tem uma característica mais abrangente e integrada dos diversos níveis da estrutura educacional. Figari (1996) afirma que a noção de estrutura define diferentes realidades, ou seja, as macroestruturas orientam os sistemas educacionais, as mesoestruturas orientam as escolas e as microestruturas orientam a sala de aula. Concorda-se com o autor quando ele define que, nos espaços da macro e da mesoestrutura, a avaliação é resultado de processo de observação e de interpretação dos resultados da aprendizagem, e que esta objetiva orientar o funcionamento da escola, dos sistemas educacionais e, também, contribuir para a formulação de políticas públicas.

Nessa mesma linha de pensamento, Afonso (2003) propõe uma análise sociológica da avaliação que compreende quatro níveis da estrutura educacional: o micro, o meso, o macro e megassociológico. Para o autor,

[...] a escola é confrontada com dimensões éticas, simbólicas, políticas, sociais e pedagógicas que devem ser consideradas como um todo por quem tem especiais responsabilidades na administração da educação, quer em nível do Estado, quer em nível municipal e local, quer em nível da própria unidade escolar. (AFONSO 2003, p. 49).

O nível microssociológico da avaliação é aquele que ocorre no âmbito da sala de aula, centrado na avaliação da aprendizagem, tendo por responsável 
o docente/professor. Seu caráter deve ser formativo, possibilitando a reflexão sobre o processo de ensino-aprendizagem. Já o nível mesossociológico da avaliação é aquele que aborda a unidade escolar, englobando todos os elementos do processo educacional, como a gestão, os processos de ensino e aprendizagem, o currículo, o docente, a comunidade, a infraestrutura, entre outros aspectos institucionais. Pode ainda ser denominada de autoavaliação da escola ou avaliação institucional interna.

A avaliação centrada na escola é uma das formas de conhecê-la e, também, sua produtividade educativa, pois o estudo sistemático do seu funcionamento lhe permite verificar a qualidade educativa que produz. É uma abordagem que deve, sobretudo, colocar em evidência o funcionamento da escola nos seus aspectos principais, como as dinâmicas organizativas, o currículo formal, o currículo oculto, os processos de ensino-aprendizagem, as relações interpessoais, as condições físicas e materiais. (BRANDALISE, 2010, p. 87).

O nível macrossociológico da avaliação é desenvolvido em âmbito nacional, verificando a qualidade do ensino e da educação em um país. O Instituto $\mathrm{Na}$ cional de Estudos e Pesquisas Educacionais (INEP) é que coordena o processo de avaliação externa às escolas no Brasil. O Sistema de Avaliação da Educação Básica (SAEB) realiza a avaliação da Educação Básica ao qual se integram, também, a Prova Brasil e a Provinha Brasil. No Ensino Médio, a avaliação é realizada, anualmente, pelo Exame Nacional do Ensino Médio (ENEM).

O nível megassociológico da avaliação é desenvolvido por organismos internacionais, os quais fixam padrões de desempenho, criam metas e diretrizes globais, como, por exemplo, o Programa Internacional de Avaliação de Alunos (PISA), que é coordenado pela Organização de Cooperação e Desenvolvimento Econômico (OCDE).

Os níveis mais globais, o megassociológico e o macrossociológico, têm um caráter de regulação, fiscalização e controle do Estado sobre as escolas e os sistemas educacionais, visto que a avaliação tem adquirido status relevante nas políticas públicas e educacionais - fenômeno caracterizado como a presença do Estado Avaliador na educação.

A educação de crianças pequenas bem como as modalidades avaliativas relativas a elas devem basear-se em necessidades e potencialidades esperadas em determinadas fases do desenvolvimento infantil (OLIVEIRA, 2002). Daí a importância do conhecimento sobre a infância e sobre o desenvolvimento infantil. As vivências educacionais nos ambientes de infância devem ser orientadas a partir das necessidades individuais de cada criança, mas também das necessidades do grupo. Por isso, os processos avaliativos devem orientar a superação de dificuldades e fragilidades do processo educacional, mas também servem para dar continuidade aos aspectos positivos. 
É importante relembrar que a LDB 9394/96, no artigo 31, estabelece como deve ocorrer a avaliação na Educação Infantil: "[...] na educação infantil a avaliação far-se-á mediante acompanhamento e registro do seu desenvolvimento, sem o objetivo de promoção, mesmo para o acesso ao ensino fundamental" (BRASIL, 1996). Percebe-se que, nesse aspecto, a avaliação serve como meio de observação para o desenvolvimento da criança, desvinculada de processos classificatórios com vistas à promoção dos alunos aos anos iniciais do Ensino Fundamental. A Educação Infantil deve trazer como pressuposto avaliativo a compreensão da criança na qualidade de ser histórico, social e produtor de cultura.

\section{Procedimentos metodológicos da pesquisa}

A pesquisa de produções científicas referente à Avaliação na/da Educação Infantil, que é o objeto deste Estado da Arte, foi realizada em meio eletrônico e em revistas impressas. O período estabelecido para a seleção de artigos, dissertações e teses publicados no Brasil foi de 2000 a 2012, considerando-se que, nos últimos anos, a produção acadêmica sobre Educação Infantil ${ }^{2}$ tem aumentado significativamente.

As dissertações e teses encontradas são oriundas de pesquisas em endereços eletrônicos, dentre eles o Scielo, o Google Acadêmico, o Portal de Periódicos da Capes, a Biblioteca Digital de Teses e Dissertações e a Fundação Carlos Chagas. Foram selecionados, também, artigos provenientes de revistas impressas, de associações, eventos e congressos regionais e nacionais, como os trabalhos apresentados na Associação Brasileira de Avaliação Educacional (ABAVE), na Associação Nacional de Pesquisa e Pós-graduação (ANPED), na Associação Nacional de Política e Administração da Educação (ANPAE) e no Congresso Internacional em Avaliação Educacional. As revistas selecionadas foram: Revista Zero a Seis (Nupein); Revista Brasileira de Educação; Revista Eccos; Revista Científica Aprender; Revista Educação; Revista Interações; Revista Iberoamericana sobre Qualidade; Eficácia e Mudança em Educação; Revista Iberoamericana de Evaluación Educativa; Revista Criança; Revista Ensaio; Revista Políticas Públicas para Educação.

A busca efetivada resultou em 47 fontes (documentos): artigos (24 $51 \%)$, dissertações $(20-43 \%)$ e teses $(3-3 \%)$. A princípio, pretendia-se que os descritores utilizados na pesquisa fossem considerados como critérios para o agrupamento das produções em categorias, mas, após a leitura e uma breve

\footnotetext{
${ }^{2}$ A Educação Infantil foi instituída como primeira etapa da Educação Básica a partir da LDB 9394/96. Com a inserção das creches e pré-escolas nos sistemas de ensino, houve a necessidade de aprofundar e produzir conhecimento sobre a educação das crianças entre 0 e 5 anos em ambientes institucionais. Dentre o material destinado a essa nova compreensão da Educação Infantil, podem ser citados os documentos: Referenciais Curriculares Nacionais para Educação Infantil (1998), Plano Nacional de Educação (2001 e 2011), Diretrizes Curriculares Nacionais para Educação Infantil (2009), bem como as Emendas Constitucionais 53/2006 e 59/2009.
} 
análise dos textos encontrados, constatou-se que nem todos apresentavam palavras-chave e resumos, razão da opção por organizá-los em quatro categorias temáticas, conforme as similaridades dos objetos de avaliação abordados e identificados no processo inicial de leitura e de análise das fontes coletadas. $\mathrm{O}$ procedimento adotado justifica-se porque uma das etapas significativas para as pesquisas do tipo "estado da arte" é a leitura e a síntese das obras selecionadas, bem como as análises que vão se orientando de acordo com o objeto de cada trabalho investigado (ROMANOWSKI, 2002).

As produções científicas que têm como temática a avaliação da aprendizagem $^{3}$ integram a categoria 1 . Na categoria 2, foram inseridos os trabalhos que discutem a avaliação institucional e/ ou de políticas e programas. A categoria 3 está constituída pelas produções científicas que tratam da avaliação na educação infantil, contemplando diferentes objetos de avaliação, exceto a avaliação da aprendizagem. Por fim, na categoria 4, estão inseridos os que tratam da avaliação na creche. A tabela 1 a seguir apresenta a distribuição das produções científicas ${ }^{4}$ por tipo e conforme as categorias definidas na pesquisa.

Tabela 1 - Produção Científica Brasileira em Avaliação na/da Educação Infantil 2000-2012

\begin{tabular}{|c|c|c|c|c|c|}
\hline 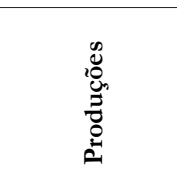 & $\begin{array}{c}\text { Avaliação da } \\
\text { Aprendizagem }\end{array}$ & $\begin{array}{c}\text { Avaliação Institucional } \\
\text { e/ou de Políticas/ } \\
\text { Programas } \\
\text { Categoria } 2\end{array}$ & $\begin{array}{c}\text { Avaliação na } \\
\text { Educação Infantil } \\
\text { Categoria } 3\end{array}$ & $\begin{array}{l}\text { Avaliação na } \\
\text { Creche } \\
\text { Categoria } 4\end{array}$ & مّ \\
\hline Artigos & 11 & 3 & 6 & 4 & 24 \\
\hline Dissertações & 6 & 2 & 10 & 2 & 20 \\
\hline Teses & 1 & 1 & 0 & 1 & 3 \\
\hline Total & 18 & 6 & 16 & 7 & 47 \\
\hline
\end{tabular}

Fonte: Dados da pesquisa.

A categoria 1, constituída da maior quantidade de produções científicas, $38 \%$, apresenta um conjunto de palavras cujas unidades de texto correspondem ao modo como é percebida e realizada a avaliação da aprendizagem na Educação Infantil. A categoria 2 representa $13 \%$ do total das produções acadêmicas. A categoria $3^{5}$, representada por $34 \%$ do total, caracteriza-se por agregar resumos

\footnotetext{
3 Para conhecimento sobre as terminologias/nomenclaturas utilizadas sobre avaliação consultar o documento Educação Infantil: subsídios para construção de uma sistemática de avaliação, publicado em outubro de 2012 pelo MEC, Disponível em: <http://portal.mec.gov.br/index.php?option=com_ content\&id=12579\%3Aeducacao-infantil\&Itemid=859>. Acesso em: 20 fev. 2013.

${ }^{4}$ A relação dos artigos, dissertações e teses que compõem o estado da arte apresentado neste artigo estão relacionados no anexo 1. Para aprofundamento, consultar a dissertação de mestrado disponível em: < http:// bicen-tede.uepg.br/tde_busca/processaPesquisa.php?pesqExecutada=1\&id=829>. Acesso em: 20 fev. 2013.

${ }^{5} \mathrm{Na}$ leitura dos resumos da categoria 3, observou-se que diferentes especificidades da Educação Infantil estão
} 
de produções científicas que discutem a avaliação relacionada aos sujeitos, aos professores, às crianças, às famílias, à qualidade de ensino ofertada, entre outros aspectos dessa etapa da Educação Básica. A categoria 4, formada por 15\% do total da produção científica, equipara-se, em quantidade, à categoria 2, revelando o número reduzido de pesquisas sobre esses objetos de avaliação. As dissertações e as teses defendidas nos programas de pós-graduação do país mapeadas estão concentradas nas regiões sudeste $(48 \%)$ e sul $(30 \%)$, e, em menor proporção, nas regiões centro-oeste $(13 \%)$ e nordeste $(9 \%)$.

Durante a organização da produção científica selecionada, constatou-se que 12 (doze) artigos não continham o resumo publicado no texto, parte do documento considerada como essencial para elaboração do estado da arte proposto na pesquisa. Decidiu-se, assim, nessa etapa, pela elaboração de resumos técnicos, os quais foram solicitados à Seção de Normalização de Trabalhos Científicos da Biblioteca da Universidade Estadual de Ponta Grossa (UEPG), a fim de garantir a eles a validade científica para integrar as fontes de análise da investigação. De posse dos resumos técnicos, optou-se pelo seu encaminhamento aos respectivos autores juntamente à apresentação dos propósitos da pesquisa e do termo de autorização para utilizá-los no seu desenvolvimento.

A busca pelo contato dos autores, inicialmente, foi feita por meio de dados contidos nas publicações, seguida do currículo lattes e das redes sociais. Nessa busca, foram localizados 10 (dez) dos 12 (doze) autores procurados, aos quais foi enviada, via e-mail, a solicitação de autorização para utilização do resumo na pesquisa. Retornaram ao solicitado apenas 5 (cinco) autores. Expirado o prazo de retorno dos autores dos resumos dos artigos, optou-se pela utilização dos resumos técnicos elaborados pela UEPG, garantindo, assim, a ética e a cientificidade no trato das fontes da pesquisa.

A partir da organização inicial das 47 produções científicas nas quatro categorias temáticas, optou-se pela sua análise com a utilização de um softwrare de análise de conteúdos denominado Analyse Lexicale par Context d'un Ensemble de Segments de Texte (ALCESTE), o qual possibilita uma classificação hierárquica descendente do material selecionado, bem como uma análise léxico gráfica do material textual.

O software realiza a leitura dos dados a partir de um único arquivo, o qual é formado por unidades de texto, chamadas de unidade de contexto inicial (UCI), as quais, coletivamente, constituem o corpus de análise do programa ALCESTE. Na

integradas à discussão sobre avaliação. Esses resumos poderiam ainda ser subcategorizados em outras temáticas, tais como: qualidade na Educação Infantil, linguagem dos relatórios, concepções e práticas na Educação Infantil, entre outros, opção esta não adotada na pesquisa.

${ }^{6}$ Para aprofundamento sobre cada etapa, consultar o texto de Brígio Vizeu Camargo: Alceste um programa informático de análise quantitativa de dados textuais, capítulo 17, do livro Perspectivas teórico-metodológicas em representações sociais, Editora UFPB, 2005. 
primeira etapa, o software realiza a leitura do texto e a sistematização das UCIs no interior do corpus, em função das ocorrências das palavras de acordo com suas raízes, e, também, calcula as frequências de cada uma delas. Em seguida, o corpus de análise é dividido pelo programa em classes de vocábulos chamadas de Unidade de Contexto Elementar (UCE), as quais, em sua maioria, são compostas de segmentos de texto com aproximadamente três linhas, dimensionadas pelo programa em função do corpus e da pontuação (CAMARGO, 2005). Nessa etapa de cálculo, as UCEs são divididas em função da frequência das formas reduzidas. Aplicado o método da classificação hierárquica descendente, cruzam-se as formas reduzidas e UCEs, gerando uma classificação definitiva, considerando o teste de associação qui-quadrado (formas reduzidas $\chi^{2} \mathrm{UCEs}$ ).

A descrição das classes de UCEs constitui a terceira e mais importante etapa operativa do ALCESTE, porque ela faz cálculos complementares para cada uma das classes gerando o dendrograma de classificação hierárquica descendente, evidenciando a existência de relação entre elas. Constituindo-se em um prolongamento da etapa anterior, na última etapa, o programa calcula e provê as UCEs mais expressivas de cada classe, contextualizando com vocabulários a classe obtida. Nessa etapa, também é possibilitada a Classificação Hierárquica Ascendente (CHA) de cada classe, permitindo a compreensão entre os elementos intraclasses. As classes geradas pelo programa são compostas de inúmeras UCEs que são precedidas do seu número de ordem no corpus e, também, de um índice de coeficiente.

Os 47 resumos pertencentes às quatro categorias definidas inicialmente foram organizados em um texto único. O processamento do corpus empírico pelo ALCESTE distinguiu as quatro classes ${ }^{7}$, originadas pela classificação hierárquica descendente. $\mathrm{Na}$ análise foram computadas $47 \mathrm{UCIs}$, que representam o total dos resumos analisados, e 289 UCEs, que são as frações de texto estabelecidas pelo programa, apresentando ao corpus um aproveitamento de $100 \%$ das análises processadas. Para análise quantitativa, foi considerado o qui-quadrado ${ }^{8}$ igual ou superior ao valor de 7,68.

\section{Avaliação na/da Educação Infantil: análise e discussão da produção científica}

A primeira partição feita pelo programa ALCESTE separou os segmentos textuais que originaram a classe 1 e a classe 3 . A classe 1 estabeleceu-se com as

\footnotetext{
${ }^{7}$ A palavra "categoria" foi utilizada na primeira etapa de organização das produções científicas conforme o objeto de pesquisa de cada uma delas. Entretanto, essas categorias passam a ser chamadas de classe, visto que a palavra "classe" é originária da classificação que o ALCESTE faz no processo de análise.

${ }^{8}$ Qui-quadrado - simbolizado por $\chi^{2}$ é um teste de hipóteses que se destina a encontrar um valor da dispersão para duas variáveis nominais avaliando a associação existente entre variáveis qualitativas. Para aprofundamento consultar: BUSSAB, W. de O.; MORETTIN, P. A. Estatística Básica. São a: Saraiva, 2002.
} 
contribuições das informações advindas dos grupos de resumos que versavam sobre a Avaliação da Aprendizagem na Educação Infantil, e a classe 3 constituiuse dos resumos de trabalhos que tratavam da Avaliação na Educação Infantil. $\mathrm{Na}$ segunda partição feita pelo programa ALCESTE, originaram-se as classes 2 e 4. A classe 2 é formada pelas palavras dos resumos que tratam de Avaliação Institucional e/ ou Politicas/Programas da Educação Infantil, e a classe 4 constituiuse das palavras oriundas dos resumos de trabalhos sobre Avaliação na Creche da Educação Infantil. A figura 1 a seguir apresenta a descrição das classes a partir das UCEs interligadas no dendograma.

Figura 1 - Dendrograma do corpus textual Avaliação na/da Educação Infantil

\begin{tabular}{|c|c|c|c|c|c|c|c|c|c|c|c|}
\hline \multirow[b]{3}{*}{$64,70 \%$} & & & & \multicolumn{3}{|c|}{ Corpus Avaliação } & & & & & \\
\hline & & & & \multicolumn{2}{|c|}{289 UCEs } & $100 \%$ & & & & & \\
\hline & & & & & & & & & \multicolumn{2}{|c|}{$35,30 \%$} & \\
\hline \multicolumn{3}{|c|}{ Classe 1} & \multicolumn{3}{|c|}{ Classe 3} & \multicolumn{3}{|c|}{ Classe 2 } & \multicolumn{3}{|c|}{$\begin{array}{l}\text { Classe } 4 \\
\end{array}$} \\
\hline \multicolumn{3}{|c|}{ Avaliação da aprendizagem } & \multicolumn{3}{|c|}{ Avaliação na educação infantil } & \multicolumn{3}{|c|}{ Avaliação Institucional } & \multicolumn{3}{|c|}{ Avaliação na creche } \\
\hline 85 UCEs & \multicolumn{2}{|c|}{$29,41 \%}$. & 102 UCEs & \multicolumn{2}{|c|}{$35.29 \%$} & 37 UCEs & \multicolumn{2}{|c|}{$12,80 \%$} & 65 UCEs & \multicolumn{2}{|c|}{$22,49 \%$} \\
\hline Palavras & Freq. & $x^{2}$ & Palavras & Freq. & $x^{2}$ & Palavras & Freq. & $x^{2}$ & Palavras & Freq. & $x^{2}$ \\
\hline porttólio & 15 & 30,10 & ensino fundamental & 6 & 11,23 & itens & 4 & 27,63 & creches & 27 & 65,04 \\
\hline sentido & 13 & 24,90 & familias & 12 & 8,27 & subescalas & 5 & 27,30 & escala & 12 & 23,97 \\
\hline aprendizagem & 22 & 21,40 & educação infantil & 43 & 7,74 & programa & 5 & 22,09 & oferecido & 5 & 17,53 \\
\hline alunos & 10 & 14,80 & mudança & 4 & 7,44 & avaliadas & 4 & 20,58 & universitária & 5 & 17,53 \\
\hline professores & 32 & 13,34 & pré-escolas & 4 & 7,44 & infantis & 4 & 10,20 & Florianópolis & 4 & 13,98 \\
\hline acompanhamento & 8 & 12,77 & realidade & 4 & 7,44 & funcionários & 3 & 10,15 & regras & 4 & 13,98 \\
\hline relatónios & 9 & 12,53 & |infância & 7 & 7,34 & educacionais & 4 & 8,33 & espaço & 10 & 12,04 \\
\hline avaliaçăo aprendizagem & 5 & 12,21 & momento & 8 & 7,02 & correlaçōes & 2 & 7,88 & neste & 8 & 10,13 \\
\hline prática & 22 & 11,51 & abordagem & 10 & 6,82 & situam & 3 & 5,80 & cotidiano & 5 & 9,86 \\
\hline registro & 13 & 10,10 & perceber & 4 & 4,45 & experiência & 4 & 5,69 & adulto & 4 & 9,65 \\
\hline importãncia & 4 & 9,73 & |trabalhos & 4 & 4,45 & meio & 4 & 5,69 & construida & 4 & 9,65 \\
\hline construção & 12 & 9,68 & criar & 5 & 4,10 & pais & 6 & 5,69 & número & 4 & 9,65 \\
\hline escola & 18 & 9,30 & referem & 5 & 4,10 & participaçäo & 6 & 5,69 & obtido & 4 & 9,65 \\
\hline significado & 5 & 8,58 & & & & ambiente & 5 & 5,16 & área & 6 & 8,36 \\
\hline semi & 6 & 8,24 & & & & adequada & 2 & 5,03 & municipal & 12 & 8,23 \\
\hline conceito & 7 & 8,22 & & & & conjunto & 2 & 5,03 & atendimento & 5 & 7,55 \\
\hline atividade & 10 & 7,53 & & & & conveniada & 2 & 5,03 & condição & 5 & 7,55 \\
\hline processo & 25 & 7,14 & & & & enfatizando & 2 & 5,03 & itens & 5 & 7,55 \\
\hline avaliação & 47 & 7,11 & & & & formecer & 2 & 5,03 & turmas & 8 & 7,35 \\
\hline aula & 4 & 6,27 & & & & periodo & 2 & 5,03 & brasileiras & 4 & 6,86 \\
\hline fundamentais & 6 & 6,21 & & & & trajetória & 2 & 5,03 & revelar & 4 & 6,86 \\
\hline visando & 6 & 6,21 & & & & documento & 3 & 4,50 & rotina & 4 & 6,86 \\
\hline concepçōes & 11 & 5,75 & & & & escala & 5 & 4,46 & etapa & 6 & 6,74 \\
\hline desenvolvimento & 18 & 4,83 & & & & grupo & 5 & 4,46 & deveriam & 3 & 6,42 \\
\hline entrevista & 8 & 4,36 & & & & & & & encontro & 3 & 6,42 \\
\hline compreensão & 5 & 4,34 & & & & & & & filantrópica & 3 & 6,42 \\
\hline docentes & 4 & 4,10 & & & & & & & movimento & 3 & 6,42 \\
\hline entendimento & 3 & 4,06 & & & & & & & padrōes & 3 & 6,42 \\
\hline facilita & 3 & 4,06 & & & & & & & recursos & 3 & 6,42 \\
\hline linha & 3 & 4,06 & & & & & & & verificar & 7 & 5,30 \\
\hline \multirow[t]{5}{*}{ londrina } & 3 & 4,06 & & & & & & & instituiçōes & 10 & 4,18 \\
\hline & & & & & & & & & presentes & 10 & 4,18 \\
\hline & & & & & & & & & mediadora & 3 & 4,11 \\
\hline & & & & & & & & & objeto & 3 & 4,11 \\
\hline & & & & & & & & & serviços & 3 & 4,11 \\
\hline
\end{tabular}

Fonte: Dados da pesquisa elaborados a partir do Relatório do ALCESTE. 


\section{Avaliação da Aprendizagem na Educação Infantil - Classe 1}

A classe 1 foi constituída pelos resumos dos trabalhos sobre avaliação da aprendizagem. Essa classe representa 29,41\% dos textos analisados na pesquisa. $\mathrm{Na}$ análise quantitativa, foi considerado o $\chi^{2} \geq 7$ e as palavras oriundas nessa primeira partição do ALCESTE, em ordem decrescente, foram: portfólio, sentido, aprendizagem, alunos, professores, acompanhamento, relatórios, avaliação da prática, registro, importância, construção, escola, significado, conceito e atividade. Essas palavras podem ser consideradas as mais significativas nessa classe e indicam um discurso voltado à avaliação como acompanhamento da aprendizagem das crianças pelos professores.

No dendrograma apresentado, foi atribuído um valor bastante significativo de $\chi^{2}$ (qui-quadrado) aos instrumentos de avaliação: portfólio, relatórios e registro. O portfólio foi a palavra com maior $\chi^{2}$ na classe de avaliação da aprendizagem na Educação Infantil, o que possibilita afirmar sua forte presença nas produções analisadas. Ele de fato é um dos instrumentos de avaliação mais adequados às especificidades do processo avaliativo nessa etapa da escolarização, porque permite a coleta e o registro de atividades realizadas pela criança em diferentes momentos e situações, e a observação e o acompanhamento do seu desenvolvimento.

O portfólio, quando desenvolvido com parceria entre professor e aluno, possibilita a reflexão sobre o ensino e a aprendizagem e, consequentemente, proporciona ao professor rever e readequar seu planejamento, se necessário. Como afirma Villas Boas (2004), o portfólio une a avaliação e o trabalho pedagógico, possibilita a interação entre alunos, professores, pais e escola, contribuindo, assim, para uma avaliação emancipatória.

O portfólio como instrumento de avaliação da aprendizagem das crianças na Educação Infantil, se construído coletivamente, tem um caráter potencializador na relação prática pedagógica e currículo. A avaliação, nessa perspectiva, é um ponto crucial do currículo e, se integrada ao processo ensino e aprendizagem, pode nortear o trabalho desenvolvido nas instituições infantis e possibilitar ao professor rever suas práticas e, também, orientar as aprendizagens individuais e coletivas de seus alunos (KRAMER, 2007).

A utilização do portfólio como instrumento de avaliação na Educação Infantil possibilita a compreensão dos processos do desenvolvimento infantil. Contudo, é preciso cuidado, porque, se mal utilizado, pode ter outro viés, favorecendo o surgimento de comparações e rótulos sobre os alunos e suas capacidades, tornando-se, assim, um instrumento para uma avaliação classificatória ou até mesmo sem sentido, uma vez que as atividades que compõem esse portfólio devem significar todo o processo de desenvolvimento do aluno, não apenas simbolizar o registro de atividades para serem apreciadas pelos pais e pela escola. 
Observam-se, ainda, por meio dos resumos analisados, que as práticas que envolvem o registro e a construção de relatórios e pareceres são práticas habituais na Educação Infantil, assim como o portfólio, porque possibilitam o acompanhamento do desenvolvimento e da aprendizagem dos alunos. Os relatórios e os registros construídos pelos professores em diferentes momentos podem registrar a prática cotidiana e informações sobre cada aluno ou da turma como um todo. Entretanto, é preciso salientar que esses instrumentos, quando utilizados como acompanhamento da aprendizagem, seguem o mesmo referencial analítico do professor, ou seja, o professor pode adotar uma postura mais behaviorista (comportamental), privilegiando o êxito, o resultado em detrimento de outros processos, ou uma concepção mais abrangente, formativa e diagnóstica, observando cada etapa de desenvolvimento da criança (ALVES, 2004). Dito de outro modo, o instrumento de avaliação utilizado não garante um processo avaliativo emancipatório, porque isso depende da concepção de avaliação do professor e da escola. Nesse sentido, chamam a atenção as palavras presentes nos resumos da classe 1: sentidos, significados, práticas, conceito, atividade. Elas revelam uma forte preocupação com os sentidos e os significados do processo de avaliação e sua importância, ou seja, a prática avaliativa construída na Educação Infantil.

A primeira classe também apresenta algumas palavras que são relacionadas à avaliação da aprendizagem como: acompanhamento e construção. Pode-se afirmar que essas ações realmente podem expressar o sentido da avaliação da aprendizagem desde que estejam realmente vinculadas a uma visão formativa, pois, como defende Afonso (2008), é ela que possibilita aos docentes acompanhar par e passo as aprendizagens dos alunos, ou seja, considerando o desenvolvimento do aluno em sua integralidade.

De acordo com as UCEs geradas no Alceste, as ações desenvolvidas voltadas à avaliação da aprendizagem permitem ajudar aos alunos no seu percurso e ao mesmo tempo estabelecer um diálogo contínuo entre o ensino e a aprendizagem. No entanto, ao trazer suas experiências avaliativas, a subjetividade do avaliador pode segregar os sujeitos desde sua primeira etapa de escolarização, visto que, muitas vezes, elas podem ter sido construídas a partir de práticas nem sempre emancipatórias, ou, em sua grande maioria, baseadas em modelos tradicionais e classificatórios. A avaliação deve possibilitar o desenvolvimento da criança, a reorganização de conhecimentos, e não pode estar centrada somente na utilização ou construção de instrumentos avaliativos (FERNANDES, 2009).

As palavras professores e alunos também foram significativas na construção dessa classe. Conforme pode ser observado no dendrograma e nas UCEs, elas expressam quais os principais sujeitos do processo de avaliação da aprendizagem. Nos processos avaliativos, os professores, de certa forma, assumem o papel de regulador das aprendizagens individuais de seus alunos, uma vez que 
necessitam estabelecer parâmetros sobre o desenvolvimento e a aprendizagem significativa. Nos textos analisados, há intenção por parte dos professores de que seja desenvolvida uma avaliação formativa da aprendizagem, não constituída apenas no objeto ou instrumento em si, mas possibilitando que a avaliação seja um primoroso instrumento de trabalho e reflexão docente, além de um elemento contribuinte ao desenvolvimento infantil.

A avaliação formativa não é uma avaliação estanque, já que deve estar articulada ao desenvolvimento de toda a ação educativa, privilegiando aos docentes a reconstrução de sua prática cotidiana, na qual estão implícitas suas práticas avaliativas, proporcionando aos alunos a elaboração e a reelaboração de aprendizagens significativas, por meio de atividades diversificadas, com propostas metodológicas e avaliativas que possibilitem o pensar, a criatividade, a autonomia, a reflexão e a emancipação (HADJI, 2005).

\section{Avaliação na Educação Infantil - Classe 3}

A classe 3 foi formada com os resumos que abordavam a Avaliação na Educação Infantil. Essa classe representou 35,29\% do total das informações analisadas nos resumos e foi constituída por 102 UCEs relacionadas, por isso se destaca tanto quanto a classe 1 . Predominaram na análise parametrada da classe 3 os seguintes elementos textuais: ensino fundamental, familia, mudanças, pré-escola, realidade, infância e momento.

As palavras contidas nos resumos analisados revelam que muitas das práticas avaliativas desenvolvidas na Educação Infantil assemelham-se a práticas avaliativas do Ensino Fundamental. Isso pode ser percebido no dendrograma, que apresenta, em ordem decrescente, as palavras bem como sua respectiva significância no corpus analisado. Esses termos mostram que há uma transferência para a Educação Infantil de concepções e de procedimentos avaliativos dos demais segmentos da Educação Básica. Talvez ainda não se tenha clareza do que significa avaliação na Educação Infantil, considerando as especificidades e as particularidades dessa etapa escolar.

As práticas avaliativas desenvolvidas na Educação Infantil, quando não estão em conformidade com as especificidades infantis, podem tornar-se práticas inadequadas e até mesmo discriminatórias, negando às crianças pequenas o direito de viver sua infância (GODOI, 2007).

A Educação Infantil originou-se não como um direito exclusivo da criança, mas sim da necessidade de um mundo capitalista no qual a mão de obra feminina tornou-se necessária. Para que as mães pudessem trabalhar, foram sendo criados ambientes específicos para deixar essas crianças. Tais ambientes, muitas 
vezes, resumiam-se a um amontoado de crianças, com idades diferentes, nos quais não havia preocupação com o desenvolvimento infantil, de modo que apenas cuidados com a alimentação e algumas práticas higienistas resumiam a atenção direcionada à criança pequena. Essas práticas capitalistas e a visão tardia de infância, que geraram uma cultura de atendimento e cuidado, contribuíram para que nas instituições de Educação Infantil fossem desenvolvidos modelos muito aproximados aos do Ensino Fundamental, buscando preparar as crianças para a vida (GODOI, 2007).

A partir das UCEs e, também, dos resumos que compõem a classe 3, constata-se que no segmento da pré-escola, destinado às crianças de 4 e 5 anos, as práticas cotidianas estão muito próximas de práticas escolarizantes, voltadas ao Ensino Fundamental, produzindo e reproduzindo uma avaliação disciplinadora, mais comportamental do que formativa. Há, portanto, uma dualidade de posturas avaliativas nesses segmentos que compõem a Educação Infantil: de um lado a creche com práticas avaliativas desvinculadas do acompanhamento do desenvolvimento das necessidades infantis; e, de outro, práticas avaliativas com caráter escolarizante inadequado para a faixa etária de 4 e 5 anos. Além disso, os resumos analisados mostram que a avaliação na Educação Infantil ainda carece de muitos estudos e pesquisas e representa uma difícil barreira a ser sobreposta nos espaços institucionais de Educação Infantil. A avaliação e outras práticas na Educação Infantil são também muito reguladoras, determinando o que pode ser ou não ser realizado (GODOI, 2007).

O dendograma também aponta que as palavras família, infância, realidade, pré-escola tiveram destaque nos resumos analisados. Na Educação Infantil, a relação família-escola é geralmente mais intensa do que nos demais níveis da Educação Básica. Pode-se inferir que os pais têm demonstrado maior interesse pela qualidade educacional das crianças pequenas em creches e pré-escolas, ou seja, muitos pais não se contentam mais apenas com a guarda e a alimentação de seus filhos em ambientes coletivos, como nas antigas instituições de Educação Infantil. Compreende-se, dessa forma, que a qualidade dos processos educacionais ultrapassa os muros da escola, pois não há como falar em qualidade, em processos avaliativos formativos em escolas que negam aos pais e à comunidade o direito de discutir o contexto educativo.

Concorda-se com Kramer (2007) quando afirma que a avaliação na Educação Infantil é uma prática construída coletivamente, integrando a escola, a família e o aluno. Essa prática, além de orientar as aprendizagens e o desenvolvimento infantil, deve possibilitar aos professores a reflexão sobre sua prática pedagógica e aos familiares o acompanhamento das aprendizagens individuais de seus filhos, modificando, assim, o papel assistencialista oferecido por muitos anos às crianças pequenas. 


\section{Avaliação institucional e de políticas/programa da Educação Infantil - Classe 2}

A classe 2 foi constituída por 37 UCEs, as quais representam $12,80 \%$ do corpus total dos dados analisados na pesquisa. Os elementos textuais com maior significância no dendograma foram: subescalas, programa, avaliadas, infantis, funcionários, educacionais e correlações, os quais revelam que as pesquisas estão voltadas à avaliação do contexto educativo.

Nos trabalhos analisados, a técnica utilizada para avaliar esses ambientes educacionais consiste no desenvolvimento e na construção de escalas e subesca$\operatorname{las}^{9}$ que contemplam diferentes aspectos das instituições infantis, como espaço e mobiliário, rotinas e cuidados pessoais, linguagem e raciocínio, atividades, interação, estrutura do programa, pais e equipe de profissionais. Apesar de não representarem necessariamente contribuições para o amplo processo que a avaliação institucional exige, a utilização dessas escalas nas pesquisas realizadas possibilitou a compreensão de que a qualidade dos ambientes educacionais infantis não se encontra com as devidas adequações para o atendimento e o desenvolvimento das crianças de zero a cinco anos.

Articular todos os processos desencadeados no interior das instituições, compreender esses processos, bem como promover a articulação entre os sujeitos que fazem parte desse lócus educativo não é tarefa simples. A utilização de instrumentos avaliativos pode ser coadjuvante na compreensão dos ambientes escolares, mas nunca deve substituir a participação dos sujeitos envolvidos no processo avaliativo. A avaliação institucional constitui-se nas relações estabelecidas pelos diferentes sujeitos tanto no micro como nos meso e macro contextos educacionais. É necessário que todos os agentes participem e aceitem esse processo (SORDI, 2009).

Ao se realizar uma primeira análise da classe 2 , tem-se a impressão de que os elementos necessários para a avaliação institucional encontram-se ali definidos. Porém, após inúmeras leituras e análise mais apurada, percebe-se um dado significativo: a ausência das palavras professor, aluno, aprendizagem ou prática pedagógica, o que possibilita afirmar que o processo educativo não se constitui como elemento necessário na perspectiva de avaliação institucional. Mesmo com o texto original apontando a necessidade de que nos processos avaliativos sejam considerados além dos pais, os profissionais e as crianças, permanece evidente o descaso com esses aspectos na proposta de avaliação institucional desenvolvida.

\footnotetext{
${ }^{9}$ As escalas norte-americanas para avaliação da qualidade em ambientes educacionais infantis, da Infant/ Toddler Environment Rating Scale - Revised Edition (ITERS-R) e da Early Childhood Environment Rating Scale - Revised Edition (ECERS-R) foram objeto de pesquisas dessa categoria.
} 
Esse resultado evidencia que a avaliação institucional na concepção proposta precisa ser repensada, pois se assenta em uma postura tradicional e necessita ser reconceituada, fugindo a modelos tradicionais que não integram o microcontexto (compreendido aqui como sala de aula) ao mesocontexto (escola) e ao macrocontexto (instituição). Existe a necessidade de articular não somente os componentes da gestão e da administração escolar, mas também os processos pedagógicos desenvolvidos no interior das instituições. Nesse sentido, faz-se alusão às palavras de Ianonne (2010), pois todas as tomadas de decisão em um ambiente escolar devem favorecer um diálogo democrático, possibilitando a interação entre os sujeitos e suas dimensões, assim como a comunidade escolar e o Estado. Enfim, a avaliação institucional abrange a análise da instituição escolar na sua totalidade, nas dimensões política, administrativa e pedagógica, tendo como base o projeto pedagógico.

Cabe ressaltar, aqui, que os estudos em avaliação institucional surgiram no início dos anos de 1990, em um momento que muito se discutia a avaliação da aprendizagem e, também, a avaliação da escola (NÓVOA, 1992). As avaliações institucionais centraram-se, inicialmente, como auxílio à avaliação de políticas e programas. O PNE 2011-2020 (BRASIL, 2011) prevê a avaliação de políticas e programas de Educação Infantil com base nos parâmetros nacionais de qualidade a fim de aferir as condições da infraestrutura física, de pessoal, de gestão, de recursos pedagógicos, mas as pesquisas revelam que não há referenciais e metodologias para que os processos avaliativos sejam conduzidos em conformidade com as finalidades e as características da Educação Infantil.

Quanto às produções científicas sobre avaliação institucional e a avaliação da creche também são raras as voltadas à Educação Infantil. Freitas (2006) afirma que avaliação institucional é um novo desafio a ser enfrentado na Educação Infantil, podendo aproximar a realidade da sala de aula à avaliação da escola e de sistemas, subentendendo-se a avaliação das políticas e dos projetos educacionais voltados a esse segmento.

\section{Avaliação na Creche da Educação Infantil - Classe 4}

A classe 4, constituída a partir de resumos sobre a Avaliação na Creche da Educação Infantil, foi formada por 65 UCEs, totalizando 22,49\% do corpus do material analisado pelo software ALCESTE. Essa classe apresenta como expressão mais significativa o termo creches, seguida das palavras escala, oferecido, regras, espaço, cotidiano, adulto, número, área, construida, municipal, atendimento, condição e itens. Por meio dos resumos analisados, e também pelas UCE's geradas pelo ALCESTE, percebe-se que a avaliação no segmento creche ainda não foi consolidada, o que contribui para a importação de mecanismos avaliativos de outros países. 
Com um qui-quadrado de 23,97, a palavra escala aparece como a segunda mais expressiva dessa classe. Nos resumos que a constituíram, percebeu-se a utilização da escala norte americana Infant/ Toddler Environment Rating Scale Revised Edition (ITERS-R) e do instrumento Child Care Facilitly Schedule (CCFS) para avaliar a qualidade nos ambientes da creche. Na escala ITERS-R, são avaliadas as dimensões do ambiente creche, como o espaço e o mobiliário, rotinas de cuidado pessoal, interação, atividades e outros. Já na escala CCFS, as dimensões avaliadas são o ambiente físico, a saúde e a segurança, a interação técnico-família, a interação técnico-aluno, entre outras.

É possível observar que a avaliação na creche, conforme descrito nos resumos, também apresenta um viés classificatório, baseado em atitudes comportamentais. Avaliações baseadas em objetivos comportamentais ou, ainda, em objetivos que privilegiam o êxito em detrimento de outros aspectos do desenvolvimento infantil são chamadas, por Alves (2004), de avaliação formativa behaviorista, ou seja, uma avaliação mensurável, não reflexiva, inadequada às especificidades infantis. Essa concepção de avaliação reduz a criança a um indivíduo que deverá ser disciplinado desde a mais tenra idade, obedecendo a regras que não contribuem ao seu desenvolvimento, nem oportunizam o desenvolvimento de juízos de moral; ao contrário, acabam por incentivar o disciplinamento dos corpos infantis e do conhecimento.

Pode-se, enfim, perceber a fragilidade da avaliação na creche, ao necessitar de escalas/modelos de outros países para tentar determinar como deve ser a avaliação na Educação Infantil, e, principalmente, pelos professores ainda avaliarem as crianças na creche a partir de atitudes comportamentais de seus alunos, desprezando ou desconhecendo outras proposições formativas de avaliação.

\section{Considerações Finais}

O propósito deste artigo foi apresentar os resultados da pesquisa sobre o estado da arte em Avaliação na/da Educação Infantil, no período compreendido entre 2000 a 2012. As produções acadêmicas brasileiras em teses, dissertações e artigos foram mapeadas a fim de compreender como os pesquisadores têm se debruçado para investigar diferentes aspectos dessa etapa da Educação Básica, quais são seus focos de interesse bem como as lacunas ou restrições existentes na produção científica da área.

O mapeamento dos trabalhos, a construção dos quadros de análise, o tratamento dos resumos dos textos selecionados e a utilização do software ALCESTE possibilitaram uma análise da produção acadêmica na área. Os termos avaliação, avaliação institucional, avaliação docente, avaliação da aprendizagem, avaliação na creche, acompanhados de educação infantil, foram utilizados na busca 
eletrônica e em publicações impressas. As produções científicas selecionadas após análise foram agrupadas em quatro grupos ou categorias de análise, sendo a primeira com 18 trabalhos sobre Avaliação da aprendizagem na Educação Infantil, a segunda com 16 trabalhos sobre Avaliação na Educação Infantil, a terceira composta pelas 6 produções voltadas à avaliação institucional e/ou de políticas/programas da Educação Infantil e a quarta com 7 trabalhos sobre a avaliação na creche da Educação Infantil, havendo predominância de artigos e dissertações sobre a temática estudada em comparação ao número de teses.

Nas produções científicas que integraram a classe da Avaliação da Aprendizagem na Educação Infantil, foi possível verificar uma preocupação com a aprendizagem das crianças pequenas e em compreender como a avaliação pode ser realizada no acompanhamento do desenvolvimento infantil. $\mathrm{Na}$ análise dos resumos com auxilio do programa ALCESTE, as palavras portfólio, sentido, aprendizagem, relatório e acompanbamento indicam a relação entre os sentidos atribuídos à aprendizagem nessa faixa etária. A avaliação, nesse período, deve ser desenvolvida pelo professor a partir de diferentes registros avaliativos.

Depreende-se da análise da quantidade de artigos e de dissertações produzidas sobre avaliação da aprendizagem na Educação Infantil que há um movimento que impulsiona os pesquisadores na busca pela produção de conhecimento sobre a avaliação do desenvolvimento da criança no primeiro segmento da Educação Básica. As universidades têm um papel muito importante tanto na formação de pesquisadores e na produção do conhecimento sobre os processos educacionais no interior das instituições de Educação Infantil. Esse movimento instituinte despertado nas universidades pode promover o debate sobre o que se espera para a educação das crianças pequenas, bem como favorecer o debate e a formulação de políticas públicas para a criança e a infância.

Assim como as pesquisas sobre a Avaliação da Aprendizagem na Educação Infantil, foram expressivas as produções científicas sobre Avaliação na Educação Infantil desenvolvidas entre 2000 e 2012. Na análise dos resumos dessa categoria, as palavras mais frequentes foram: ensino fundamental, famílias, educação infantil, mudanças, pré-escola, realidade, infância e momento. A relação que se pode estabelecer entre elas é que a avaliação na Educação Infantil deve respeitar o momento da infância pelo qual passam as crianças dessa fase escolar. As mudanças políticas, econômicas e sociais afetaram a realidade das famílias que precisam deixar seus filhos nos espaços institucionais de Educação Infantil, que passaram a ter mais consciência da função educativa que lhes é atribuída, ao mesmo tempo em que possibilita a exigência de uma educação de mais qualidade, sem a característica do simples atendimento e cuidado de caráter assistencialista de outrora.

Outro aspecto observado nas produções científicas analisadas é quanto às concepções e práticas avaliativas na Educação Infantil. Como avaliar 
e acompanhar o desenvolvimento da criança, o que e por que avaliar são questionamentos constantes dos profissionais da Educação Infantil, porque há uma tendência de transferir para esse segmento as concepções e as práticas de avaliação escolar adotadas no Ensino Fundamental, negando, de certa forma, as características específicas do desenvolvimento infantil. A avaliação precisa possibilitar às crianças agir em seu processo educativo, ou seja, elas devem ser envolvidas nas práticas avaliativas e em seus registros. Isso implica que os professores compreendam as crianças como sujeitos de direitos, como seres em desenvolvimento, com características únicas, devendo ser avaliadas, portanto, pelo que são no presente momento e não pelo modelo que espera por elas nos anos seguintes do Ensino Fundamental.

A análise parametrada realizada pelo ALCESTE revelou que há forte articulação entre as produções científicas das duas classes: Avaliação da Aprendizagem na Educação Infantil e Avaliação na Educação Infantil. Elas são voltadas ao contexto dos ambientes no qual se desenvolve o processo educativo, ou seja, as pesquisas estão voltadas ao micronível do contexto escolar.

As produções científicas sobre a Avaliação Institucional e/ou de Políticas/programas da Educação Infantil e sobre a Avaliação na Creche da Educação Infantil, no dendograma gerado pelo ALCESTE, tiveram fraca correlação com temáticas das categorias anteriores. As palavras creches, escala, oferecido, regras, espaço, cotidiano, adulto, atendimento, condição e itens revelam o sentido atribuído à avaliação nessas categorias. As palavras evidenciam uma concepção de avaliação tradicional, classificatória e as práticas avaliativas muitas vezes são baseadas somente na observação das atitudes comportamentais das crianças na tentativa de discipliná-las, de cumprir regras, por exemplo, a como andar, brincar, comer e até mesmo dormir. Nessa categoria, a ênfase em escalas e em indicadores quantitativos chamou a atenção para a avaliação dos ambientes de Educação Infantil, aliada à proposição de utilização de modelos de escalas americanas para avaliar a qualidade da creche na realidade brasileira, desconsiderando nossos contextos institucionais e nossa cultura.

Em virtude da escassa produção científica sobre a avaliação na creche, pode-se inferir que muitos dos processos avaliativos desenvolvidos com as crianças de 0 a 3 anos são tradicionais, escolarizantes e não formativos. Ao contrário, promovem a avaliação em uma perspectiva descritiva e de julgamento, no qual os aspectos comportamentais são mais importantes do que aprendizagens significativas.

A avaliação institucional e/ou de políticas/ programas é a área temática mais carente de produções científicas em avaliação da Educação Infantil. As palavras mais significativas encontradas - subescalas, itens, programa -, também estão 
relacionadas à utilização das escalas americanas (ITERS-R e ECERS-R) para avaliação da instituição de Educação Infantil. Os trabalhos apontam que, por mais que essas escalas contemplem vários itens, deve-se ter em mente que avaliar uma instituição ou um programa envolve questões de ordem político-pedagógica, administrativa e estrutural, indo muito além das avaliações dos contextos microssociológicos: sala de aula, professor e aluno.

Com a possibilidade de ser desenvolvida por agentes externos à escola ou pela própria instituição, a avaliação institucional deve promover a interação de todos os elementos que constituem a escola. Se desenvolvida em uma perspectiva formativa e integrada pode valorizar os contextos nos quais as informações e resultados são gerados, possibilitando reflexões, discussões e proposições para a reconstrução das práticas, a partir da negociação do coletivo escolar. A avaliação na Educação Infantil não é e nem deve estar associada somente à avaliação do aluno ou à avaliação da aprendizagem. Ao perceber a escola como um espaço formado por crianças, adultos, por um contexto social e local, torna-se imprescindível compreender todas as relações desenvolvidas no interior dessas instituições.

A escola é formada por diferentes sujeitos, dentre eles, pais, alunos, professores, diretores, coordenadores pedagógicos, cozinheiras, auxiliares de limpeza e toda comunidade ao redor da instituição. Todas essas pessoas fazem parte desse contexto institucional e devem fazer parte dos processos avaliativos nele desencadeados. A avaliação na Educação Infantil deve contemplar todos os sujeitos desse espaço, pois eles fazem a escola, eles são a escola. Assim, percebe-se que a avaliação na Educação Infantil deve ser desenvolvida de maneira que integre todos os aspectos da instituição, e isso somente será possível com a articulação entre os sujeitos e o espaço no qual cada um tem consciência de sua necessidade ao bom funcionamento institucional.

Por fim, a pesquisa realizada evidenciou que o foco das produções em avaliação na Educação Infantil está voltado à avaliação do acompanhamento do desenvolvimento das crianças, ou seja, para avaliação da aprendizagem, seus procedimentos e seus instrumentos. Nas demais áreas, avaliação de currículo, avaliação docente, avaliação institucional e de políticas e programas, a produção acadêmica ainda é escassa. Outro aspecto importante desvelado na pesquisa é que é preciso respeitar a singularidade da Educação Infantil, a criança e a infância quando se trata da Avaliação na/da Educação Infantil.

\section{Referências}

AFONSO, A. J. Avaliação educacional: regulação e emancipação para uma sociologia das políticas avaliativas contemporâneas. 2. ed. São Paulo: Cortez, 2000. 
AFONSO, A. J. Avaliar a escola e a gestão escolar: elementos para uma reflexão crítica. In: ESTEBAN, M. T. (Org.). Escola, currículo e avaliação. São Paulo: Cortez, 2003, p. 38-56.

AFONSO, A. J. Escola pública, comunidade e avaliação: resgatando a avaliação formativa como instrumento de emancipação. In: ESTEBAN, M. T. (Org.). Avaliação: uma prática em busca de novos sentidos. 6. ed. Petrópolis: Anthares, 2008, p. 67-80.

ALVES, M. P. C. Currículo e avaliação: uma perspectiva integrada. Porto: Porto, 2004.

BUSSAB, W. de O.; MORETTTIN, P. A. Estatística básica. 5. ed. São Paulo: Saraiva, 2002.

BRANDALISE, M. Â. T. Autoavaliação de escolas: alinhavando sentidos, produzindo significados. Ponta Grossa: UEPG, 2010.

BRASIL. Constituição da República Federativa do Brasil: promulgada em 5 outubro de 1988. Brasília: Senado, 1988.

BRASIL. Lei n. 9.394, de 20 de dezembro de 1996. Estabelece as Diretrizes e Bases da Educação Nacional. Brasília, 1996.

BRASIL. Emenda Constitucional n ${ }^{\circ}$ 59, de 11 de novembro de 2009. Disponível em: <http://www.planalto.gov.br/ccivil_03/constituicao/Emendas/Emc/emc59.htm>. Acesso em: 12 set. 2012.

BRASIL. Ministério da Educação. Secretaria de Educação Básica. Diretrizes Curriculares Nacionais para Educação Infantil. Brasília: MEC/SEB, 2010.

BRASIL. Projeto de Lei do Plano Nacional de Educação (PNE 2011/2020). Projeto em tramitação no Congresso Nacional / PL n ${ }^{\circ} 8.035$ de 2010. Organização de Márcia Abreu e Marcos Cordiolli. Brasília: Câmara dos Deputados, Edições Câmara, 2011. (Série ação parlamentar, n. 436).

CAMARGO, B. V. Alceste: um programa informático de análise quantitativa de dados textuais. In: MOREIRA, A. S. P.; CAMARGO, B. V.; JESUINO, J. C.; NÓBREGA, S. M. da (Orgs.). Perspectivas teórico-metodológicas em representações sociais. João Pessoa: Universitária-UFPB, 2005. p. 511-539.

FERNANDES, D. Avaliar para aprender: fundamentos, práticas e políticas. São Paulo: UNESP, 2009.

FIGARI, G. Avaliar: que referencial? Porto: Porto, 1996.

FREITAS, L. C. de F. Diferentes âmbitos da avaliação. Revista Pátio Educação Infantil, Porto Alegre, v. IV, n. 10, p. 15-17, mar./jun. 2006.

GODOI, E. G. A avaliação e a educação de crianças pequenas. Revista Pátio Educação Infantil, Porto Alegre, v. 4, n. 12, p. 34-36, nov./fev. 2007.

HADJI, C. Por uma avaliação mais inteligente. Revista Pátio, Porto Alegre, v. 9, n. 34, p. 10-15, maio/jul. 2005.

IANNONE, L. R. Avaliação institucional: cenário, fundamentação e práticas. In: CAPPELLETTI, I. F. Avaliação e currículos: políticas e projetos. São Paulo: Articulação Universidade/Escola, 2010. p. 25-49.

KRAMER, S. (Org.). Com a pré-escola nas mãos: uma alternativa curricular para a educação infantil. 14. ed. São Paulo: Ática, 2007. 
NÓVOA, A. As organizações escolares em análise. Lisboa: Publicações Dom Quixote, 1992.

OLIVEIRA, Z. R. de. Educação Infantil: fundamentos e métodos. São Paulo: Cortez, 2002.

ROMANOWSKI, J. P. As licenciaturas no Brasil: um balanço das teses e dissertações dos anos 90. 2002. 132 f. Tese (Doutorado em Educação) - Faculdade de Educação da Universidade de São Paulo, São Paulo, 2002.

SORDI, M. R. L.; SOUZA, E. S. A avaliação institucional como instância mediadora da qualidade da escola pública: a rede municipal de Campinas como espaço de aprendizagem. Campinas: Millennium, 2009. p. 13-34.

VILLAS BOAS, B. M. de F. Portfólio, avaliação e trabalho pedagógico. Campinas: Papirus, 2004.

Anexo - Relação das produções científicas por categoria

\section{Relação das produções científicas da categoria 1} Avaliação da aprendizagem na/da Educação Infantil

1 ARAGÃO, Rosana. O portfólio como novo instrumento de avaliação. Revista criança, Brasília, n. 41, p. 14-17, nov. 2006.

2 BARBOSA, Maria Carmen Silveira. O acompanhamento das aprendizagens e a avaliação. Revista Pátio Educação Infantil, Porto Alegre, ano 2, n. 4, abr./jul. 2004.

COELHO, Maria Fernanda D’avila. O acompanhamento da aprendizagem na Educação Infantil:

3 uma questão de avaliação. 2009. 127 f. Dissertação (Mestrado em Educação) - Universidade do Vale do Itajaí, Itajaí, 2009.

COLASANTO, Cristina Aparecida. A linguagem dos relatórios: uma proposta de avaliação para

4 Educação Infantil. 2007. 137 f. Dissertação (Mestrado em Linguística Aplicada e Estudos de Linguagem) - Pontifícia Universidade Católica de São Paulo, São Paulo, 2007.

5 CORRÊEA, Eloiza Schumacher. A avaliação entre, através e além das linguagens plásticas. Revista Pátio Educação Infantil, Porto Alegre, ano IV, n. 10, p.38-41, mar./jun. 2006.

6 FERNANDES, Claudia de Oliveira. Avaliação sempre envolve uma concepção de mundo. Revista criança, Brasília, n. 41, p. 9-11, nov. 2006.

FERRI, Márcia Barcellos. Qualidade na Educação Infantil: crítica aos mecanismos de avaliação do pro-

7 fessor. In: Políticas Públicas e Gestão da Educação: Construção Histórica, Debates Contemporâneos e Novas Perspectivas, 24., 2011, São Paulo. Anais... São Paulo: ANPAE, 2011.

GUEDES, Adrianne Ogêda. Elaboração e organização de instrumentos de acompanhamento e avalia-

8 ção da aprendizagem e desenvolvimento das crianças. Revista criança, Brasília, n. 41, p. 12-13. nov. 2006.

LUSARDO, Raquel Costa Cardoso. Avaliação em Educação Infantil: concepções de professoras

9 sobre o papel do portfólio. 2007. 128 f. Dissertação (Mestrado em Educação) - Universidade Federal de Juiz de Fora, Juiz de Fora, 2007.

MOURA, Ellen Michelle Barbosa. A avaliação na Educação Infantil e sua relação com os pro-

10 cessos de aprendizagem. 2007. 173 f. Dissertação (Mestrado em Educação) - Universidade Federal Fluminense, Rio de Janeiro, 2007.

NONO, Maévi Anabel. Avaliação na Educação Infantil - legislação e pesquisas. Disponível

11 em: <http://www.acervodigital.unesp.br/bitstream/123456789/298/1/01d13t09.pdf>. Acesso em: 02 abr. 2012.

RAIZER, Cassiana Magalhães. Portfólio na Educação Infantil: desvelando possibilidades para a

12 avaliação formativa. 2007. 169 f. Dissertação (Mestrado em Educação) - Universidade Estadual de Londrina, Londrina, 2007. 
conclusão

\section{Relação das produções científicas da categoria 1} Avaliação da aprendizagem na/da Educação Infantil RAMIRES, Jussara Martins Silveira. A construção do portfólio de avaliação em uma escola mu3 nicipal de Educação Infantil de São Paulo: um relato crítico. 2008. 292 f. Tese (Doutorado em Educação) - Universidade de São Paulo, São Paulo, 2008.

SANTÁREM, Maria Solange Portela; CRUZ, Maricélia Silva da. Avaliação formativa na Educação Infantil. Disponível em: <http://www.pedagobrasil.com.br/pedagogia/avaliacaoformativa.htm>. Acesso em: 2 abr. 2012.

SILVA, Dulcinéia Barbosa da; SILVA, Greyce Kelly Ferreira; FERRAZ, Bruna Tarcília. A função do registro avaliativo na Educação Infantil. Disponível em: <http://www.ufpe.br/ce/images/Graduacao_pedagogia/pdf $/ 2008.2 / \mathrm{a} \% 20$ funo $\% 20$ do $\% 20$ registro $\% 20$ avaliativo $\% 20$ na $\% 20$ educao $\% 20$ infantil.pdf>. Acesso em: 03 maio 2012.

STEINLE, Marlizete Cristina Bonafini; SOUZA, Nádia Aparecida de. Avaliação formativa e o proces-

16 so de ensino/aprendizagem na Educação Infantil. Estudos em avaliação educacional, v. 18, n. 36, p. 63-74, jan./abr. 2007.

STEINLE, Marlizete Cristina Bonafini. Avaliação da aprendizagem: contemplando o universo da

17 Educação Infantil. 2006. 142 f. Dissertação (Mestrado em Educação) - Universidade Estadual de Londrina, Londrina, 2006.

18 VALIATI, Márcia Elisa. A avaliação como uma experiência compartilhada. Revista Pátio Educação Infantil, Porto Alegre, v. 2, n. 4, p. 40-43, abr./jul. 2004.

\begin{tabular}{|c|c|}
\hline \multicolumn{2}{|r|}{$\begin{array}{l}\text { Relação das produções científicas da categoria } 2 \\
\text { Avaliação Institucional e /ou de Políticas / Programas da Educação Infantil - } 2013\end{array}$} \\
\hline 1 & $\begin{array}{l}\text { CERISARA, Ana Beatriz; ROCHA, Eloísa Acires Candal; SILVA FILHO, João Josué da. Educação } \\
\text { Infantil: uma trajetória de pesquisa e indicações para a avaliação de contextos educativo. Revista Zero- } \\
\text {-a-seis, Florianópolis, n. } 15 \text {, p. } 1-25 \text {, jan./jun. } 2007 \text {. }\end{array}$ \\
\hline 2 & $\begin{array}{l}\text { CIASCA, Maria Izabel Filgueiras Lima. Qualidade na Educação Infantil: proposta de avaliação } \\
\text { institucional em busca de novos rumos. 2003. } 253 \text { f. Tese (Doutorado em Educação) - Universidade } \\
\text { Federal do Ceará, Fortaleza, 2003. }\end{array}$ \\
\hline 3 & $\begin{array}{l}\text { PEREIRA, Arlete Santana. Avaliação da qualidade em ambientes educacionais: o caso do progra- } \\
\text { ma de Educação Infantil. 2005. } 99 \text { f. Dissertação (Mestrado em Educação) - Universidade Federal de } \\
\text { Minas Gerais, Belo Horizonte, } 2005 \text {. }\end{array}$ \\
\hline 4 & $\begin{array}{l}\text { RAMPAZZO, Wania Cristina Tedeschi. Avaliação institucional na Educação Infantil: um campo } \\
\text { de possibilidades. Disponível em: <www.anped.org.br/reunioes/31 ra/2poster/GT07-4227--Int.pdf>. } \\
\text { Acesso em: } 2 \text { abr. } 2012 \text {. }\end{array}$ \\
\hline 5 & $\begin{array}{l}\text { RIBEIRO, Bruna. A qualidade na Educação Infantil: uma experiência em autoavaliação em creches } \\
\text { da cidade de São Paulo. 2007. } 198 \text { f. Dissertação (Mestrado em Educação) - Pontifícia Universidade } \\
\text { Católica de São Paulo, São Paulo, 2010. }\end{array}$ \\
\hline 6 & $\begin{array}{l}\text { ROSEMBERG, Fúlvia. Avaliação de programas, indicadores e projetos em Educação Infantil. Revista } \\
\text { Brasileira da Educação, Rio de janeiro, n. 16, p. 19-26, jan./abr. } 2001 .\end{array}$ \\
\hline
\end{tabular}

\section{Relação das produções científicas da categoria 3} Avaliação na Educação Infantil - 2013

ALVES, Fábio Tomaz. O processo de avaliação das crianças no contexto da Educação

1 Infantil. 2011. 346f. Dissertação (Mestrado em Educação) - Universidade Federal de Santa Catarina, Florianópolis, 2011.

BARROS, Aline Paes de. Processos de avaliação do trabalho na Educação Infantil: uma experiência com

2 o processo de construção participativa dos indicadores de qualidade. In: Encontro de Pesquisadores do Programa Educação: Currículo, 10., 2011, São Paulo. Anais... São Paulo: PUC, 2011. 
conclusão

Relação das produções científicas da categoria 3 Avaliação na Educação Infantil - 2013

3 de uma experiência. 2002, 120f. Dissertação (Mestrado em Educação) - Universidade Estadual de Londrina, Londrina, 2002.

CIASCA, Maria Isabel Filgueira Lima; MENDES, Débora Lúcia Lima Leite. Estudos de avaliação na

4 Educação Infantil. Estudos em avaliação educacional, São Paulo, v. 20, n. 43, p. 293-304, maio/ ago. 2009.

CORRÊA, Maria Theresa de Oliveira. Avaliação e a qualidade da Educação Infantil: uma análise

5 dos processos avaliativos desenvolvidos na creche e na pré-escola. 2007. 248 f. Dissertação (Mestrado em Educação) - Universidade de Brasília, Brasília, 2007.

COSTA, Saionara. A interação professor-criança na Educação Infantil: contribuições para o

6 processo de autoavaliação na formação docente. 2006. 182 f. Dissertação (Mestrado em Educação) Universidade do Vale do Itajaí, Itajaí, 2006.

7 DIDONET, Vital. Coerência entre avaliação e finalidades da Educação Infantil. Revista Pátio Educação Infantil, Porto Alegre, ano IV, n. 10, p. 46-47, mar./jun. 2006.

8 DINIZ, Andrea Morais. Avaliação e diálogo: percurso e prática na escola infantil. 2002. 180 f. Dissertação (Mestrado em Educação) - Universidade Federal do Rio Grande do Norte, Natal, 2002.

9 GALLO, Bruna Calefi. Qualidade na Educação Infantil pública: concepções das famílias usuárias. 2010. 120 f. Dissertação (Mestrado em Psicologia) - Universidade de São Paulo, Ribeirão Preto, 2010.

10 GODOI. Elisandra Girardelli. Educação Infantil: avaliação escolar antecipada? 2000. 193 f.

0 Dissertação (Mestrado em Educação) - Universidade Estadual de Campinas, Campinas. 2000.

MORAES, Andra Leal Ferreira de. Avaliação na Educação Infantil: concepções e práticas dos

11 professores dos centros municipais de Educação Infantil de Goiânia. 2003. 165 f. Dissertação (Mestrado em Educação) - Universidade Federal de Goiás, Goiânia, 2003.

PAZ, Senhorinha de Jesus Pit. A Avaliação na Educação Infantil: análise da produção acadêmica

12 brasileira presente nas reuniões anuais da ANPED entre 1993 e 2003. 2005. 132 f. Dissertação (Mestrado em Educação) - Universidade Federal de Santa Catarina, Florianópolis, 2005.

REINALDO, Evellyze Martins; OLIVEIRA Tereza Raquel Santos de. Algumas reflexões avaliativas

13 sobre Educação Infantil. In: Congresso Internacional de Avaliação Educacional, 5., 2010, Fortaleza. Anais... Fortaleza: Imprece, 2010. p. 2405.

RODRIGUES, Sílvia Adriana; GARMS, Gilza Maria Zauhy. Concepções e metodologias de

14 avaliação na Educação Infantil: os percalços e os desafios da atualidade. In: Encontro Latino Americano de Iniciação Científica e Encontro Latino Americano de Pós-Graduação, 10., 2006, São José dos Campos. Anais eletrônicos... São José dos Campos, 2006. p. 2309-2312.

SANTOS, Marceli D’andrea. A linguagem lúdica no registro avaliativo do educador de infância.

15 2008. 106 f. Dissertação (Mestrado em Educação) - Universidade Federal de Mato Grosso do Sul, Campo Grande, 2008.

SILVA, Ilda de Carvalho; FRANÇA, Rodrigo Marcellino de. Um olhar sensível e reflexivo da avaliação

16 na Educação Infantil. Revista de divulgação técnico-científica do ICPG, v. 3, n. 9, p. 67-72, jul./ dez. 2006.

Relação das produções científicas da categoria 4 Avaliação na Creche da Educação Infantil - 2013

1 COLASANTO, Cristina Aparecida. Relatório de avaliação na Educação Infantil: um estudo sobre a linguagem argumentativa. Educação teoria e prática, Rio Claro, v. 15, n. 27, p. 153-163, jul./dez. 2006.

FIGUEIREDO, Ivoneide Gomes. Avaliação da qualidade de creches: estudo em um município de

2 São Paulo. 2010. 137 f. Dissertação (Mestrado em Distúrbios do Desenvolvimento) - Universidade Presbiteriana Mackenzie, São Paulo, 2010. 
conclusão

Relação das produções científicas da categoria 4

Avaliação na Creche da Educação Infantil - 2013

3 GODOI, Elisandra Girardelli. Avaliação na creche: o disciplinamento dos corpos e a transgressão das crianças. Educação teoria e prática, Rio Claro, v. 20, n. 35, p. 21-37, jul./dez. 2010.

4 GODOI, Elisandra Girardelli. Avaliação na creche: o caso dos espaços educativos não-escolares. 2006. 235 f. Tese (Doutorado em Educação) - Universidade Estadual de Campinas, Campinas, 2006.

ROCHA, Eloísa Acires Candal; STRENZEL, Giandréa Reuss. Indicadores para a avaliação de con-

5 textos educativos em creche: articulando pesquisa pedagógica e formação profissional. Disponível em: <www.anped.org.br/reunioes/25/.../eloisaacirescandalrochap07.rtf>. Acesso em: 02 abr. 2012.

SILVA, Juliana Bezzon da; SOUZA, Tatiana Noronha de. Análise da utilização de uma escala para

6 avaliação da qualidade de creches. Estudos em Avaliação Educacional, São Paulo, v. 22, n. 48, p. 137-158, jan./abr. 2011.

SILVEIRA, Scheila Machado da. Qualidade do atendimento de creches: análise de uma escala de

7 avaliação. 2009. 144 f. Dissertação (Mestrado em Educação) - Faculdade de Filosofia, Ciências e Letras de Ribeirão Preto, Universidade de São Paulo, Ribeirão Preto, 2009.

Recebido em 01/02/2013

Versão final recebida em 10/03/2014

Aceito em 17/03/2014 